\title{
Open Market Operations and the Federal Funds Rate
}

\author{
Daniel L. Thornton
}

\begin{abstract}
It is commonly believed that the Fed's ability to control the federal funds rate stems from its ability to alter the supply of liquidity in the overnight market through open market operations. This paper uses daily data compiled by the author from the records of the Trading Desk of the Federal Reserve Bank of New York over the period March 1, 1984, through December 31, 1996: He analyzes the Desk's use of its operating procedure in implementing monetary policy and the extent to which open market operations affect the federal funds rate-the liquidity effect. The author finds that the operating procedure was used to guide daily open market operations; however, there is little evidence of a liquidity effect at the daily frequency and even less evidence at lower frequencies. Consistent with the absence of a liquidity effect, open market operations appear to be a relatively unimportant source of liquidity to the federal funds market. (JEL E43, E52)
\end{abstract}

Federal Reserve Bank of St. Louis Review, November/December 2007, 89(6), pp. 549-70.

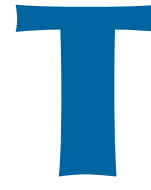
he conventional view is that the Fed controls the federal funds rate by altering the supply of liquidity in the overnight market by changing the supply of reserves relative to demand through open market operations (e.g., Taylor, 2001, Friedman, 1999). Open market operations are conducted by the Trading Desk of the Federal Reserve Bank of New York (the Desk). Although the procedure that the Desk follows has evolved and continues to do so, the fundamental procedure has remained largely the same since at least the mid-to-late 1970s. Specifically, the Desk estimates (i) the demand for reserves that are required to achieve the Federal Open Market Committee (FOMC)'s operating objective and (ii) the quantity of reserves that would be available if the Desk did nothing. If (i) exceeds (ii), the procedure indicates that reserves should be added through an open market purchase of government securities. If (i) is less than (ii), the procedure suggests that the Desk drain reserves through an open market sale.
It is important to note that the operating procedure is intended only to provide the Desk with guidance in conducting daily open market operations. It was never intended to be strictly adhered to. Specifically, frequent, yet informal, adjustments to the estimate of excess reserves were made. ${ }^{1}$ Moreover, the Desk's behavior is also guided by other factors, such as its estimate of free reserves, in determining the day's open market operations.

This paper uses daily data compiled by the author from the records of the Desk to analyze the effect of open market operations. ${ }^{2}$ The paper addresses two issues: the use of the operating

1 These informal adjustments were stated in the morning call and depended on estimates of the distribution of cumulative excess reserves holding to date. These informal adjustments were particularly important on the last two days of the maintenance period.

2 The Federal Reserve Bank of New York and the Board of Governors (BOG) of the Federal Reserve System jointly control the access to and the use of these data. I thank Jonathan Albrecht and Joanna Barnish for their valuable assistance in gathering these data and John Partlan for helping me understand the nuances of the Desk's operating procedure.

Daniel L. Thornton is a vice president and economic policy advisor at the Federal Reserve Bank of St. Louis. He thanks John Partlan and Sherry Edwards for comments and John McAdams for research assistance. An earlier version of this article was published in D.G. Mayes and J. Toporowski, eds., Open Market Operations and Financial Markets. Abingdon and New York: Routledge, 2007, pp. 178-202.

(C) 2007, The Federal Reserve Bank of St. Louis. Articles may be reprinted, reproduced, published, distributed, displayed, and transmitted in their entirety if copyright notice, author name(s), and full citation are included. Abstracts, synopses, and other derivative works may be made only with prior written permission of the Federal Reserve Bank of St. Louis. 
procedure in implementing monetary policy and the extent to which open market operations affect the federal funds rate-the liquidity effect. In so doing, it provides some evidence on the relative importance of Fed operations in supplying liquidity to the federal funds market.

The next section presents a detailed analysis of the Desk's operating procedure and its use of the procedure. The following sections investigate the relationship between open market operations and the federal funds rate and analyze these findings.

\section{THE DESK'S OPERATING PROCEDURE}

The equilibrium federal funds rate is determined by the demand for and supply of total reserves. Hence, the Desk's operating procedure under a federal funds targeting procedure is simply to equate the supply of reserves with the expected demand, conditional on the target for the federal funds rate. To illustrate the procedure, assume that the demand for total reserves $\left(T R^{d}\right)$ is given by

$$
T R_{t}^{d}=f\left(f f_{t}, x_{t}\right)+\eta_{t},
$$

where $f f_{t}$ is the federal funds rate, $x_{t}$ is a vector of other variables that determine reserve demand, and $\eta_{t}$ is a random i.i.d. demand shock. Implicitly, the demand for reserves includes the demand for excess reserves-reserves in excess of those needed to satisfy Federal Reserve-imposed reserve requirements.

The quantity of total reserves supplied if the Desk conducts no open market operations is determined by the Fed's holding of government securities, $B_{t}$, borrowing by depository institutions, $B R_{t}$, and what the Desk refers to as autonomous factors that affect reserve supply, $F_{t}$ (e.g., currency in circulation, the Treasury's balance at the Fed, and float). ${ }^{3}$ That is,

3 Borrowing (and later, the initial borrowing assumption) refers to seasonal plus adjustment borrowing. Extended credit borrowing was treated separately, as one of the autonomous factors affecting reserve supply.

$$
T R_{t}^{s}=B_{t}+B R_{t}+F_{t}
$$

In practice, the Desk knows the magnitude of none of the variables on the right-hand side of (2) at the time that it conducts open market operations; however, because the errors are very small for $B_{t}$, for the sake of this analysis $B_{t}$ is assumed to be known exactly. ${ }^{4}$ The Desk makes an estimate of the autonomous factors that affect reserve supply, i.e., $E_{t-1} F_{t}=F_{t}+v_{t}$, where $E_{t-1}$ denotes the expectation operator conditional on information available before that day's open market operation and $v_{t}$ denotes the forecast miss. The Desk does not estimate borrowing, but rather applies the FOMC-determined borrowing assumption, called the initial borrowing assumption $\left(I B A_{t}\right) .^{5,6}$ Given these assumptions and definitions, the estimate of reserve supply if the Desk conducts no open market operations is given by

$$
E_{t-1} T R_{t}^{s}=B_{t}+E_{t-1} F_{t}+I B A_{t} .
$$

The amount of the open market operations suggested by the Desk's operating procedure, which I call the operating procedure-determined open market operation $\left(O P D O M O_{t}\right)$, is given by

(4) $O P D O M O_{t}=E_{t-1} f\left(f f_{t}^{*}, x_{t}\right)-\left(E_{t-1} N B R_{t}+I B A_{t}\right)$,

\footnotetext{
4 The reason is that the Desk assumes that there would be no purchases or sales on foreign accounts that day. The foreign desk, however, has permission to make sales during the day up to some specified amount. The foreign desk is not permitted to make purchases on the System account, however. Purchases are executed in the secondary market to neutralize their impact on reserves.

5 Thornton (2006) shows that borrowed reserves targeting was a euphemism for federal funds rate targeting. He also notes that the IBA was last mentioned in discussing monetary policy during a conference call on January 9, 1991. Despite this fact, the FOMC never formally announced it was no longer targeting borrowed reserves and a borrowing assumption remained part of the Desk's formal operating procedure until at least the end of our sample period. However, it is no longer used today. Also, compare the discussion of "operating procedures" in Sternlight (1991) with Sternlight (1992).

6 The IBA is changed relatively infrequently and most often when the funds rate target is changed (see Thornton, 2001b, for an analysis of the connection between the IBA and changes in the funds rate target). Separate estimates of the demand for required and excess reserves are made. Like the IBA, the estimate of the demand for excess reserves is changed infrequently. In contrast, the estimate of the demand for required reserves is typically changed six times during each maintenance period.
} 
where $f f_{t}^{*}$ denotes the Fed's target for the federal funds rate and $E_{t-1} N B R_{t}=B_{t}+E_{t-1} F_{t}$ is the expected level of nonborrowed reserves. ${ }^{7}$ If $O P D O M O_{t}$ is positive, the procedure directs the Desk to purchase government securities to keep the funds rate at the targeted level. If it is negative, the procedure indicates government securities should be sold.

\section{An Evaluation of the Desk's Operating Procedure}

The Desk's use of its operating procedure is analyzed using daily estimates of $O P D O M O_{t}$ during the period March 1, 1984, through December 31, 1996. In practice, the staffs of the New York Fed and the BOG made separate estimates of the maintenance-period demand for reserves and the supply of nonborrowed reserves. Hence, there are two separate estimates of procedure-determined open market operations for the day. Because there are more observations available for the BOG estimates, only the BOG's estimates are used here. ${ }^{8}$ However, the qualitative conclusions are essentially unchanged when the New York Fed estimates are used. This is not surprising because the correlations between these alternative estimates of reserve supply and demand are 0.9986 and 0.9996, respectively.

Reserve Requirement Changes. There were two major changes in reserve requirements during the sample period. The first occurred on December 13, 1990, when reserve requirements on non-personal time and saving deposits and net eurocurrency liabilities were reduced from 3 percent to zero over two maintenance periods.

\footnotetext{
7 This terminology stems from the fact that, before June 1995, the borrowed reserves assumption was presented in each of the policy alternatives voted on by the FOMC. The borrowing assumption was frequently stated in terms of a range for borrowed reserves, rather than a specific level. The level used by the Desk was often (but not always) the midpoint of the range voted on by the FOMC. Moreover, the borrowing assumption was often changed during the intermeeting period without a specific vote of the FOMC. Beginning with the June 30, 1995, meeting, the FOMC dropped the explicit reference to the level of seasonal plus adjustment borrowing that it believed was consistent with the policy alternatives being considered.

8 There are 19 missing observations for the BOG and 586 missing observations for the New York Fed. Also, there are seven days when daily open market operations are missing.
}

The second occurred on April 2, 1992, when the reserve requirement on transactions deposits was reduced from 12 percent to 10 percent. The first of these was a surprise move. It took time for banks to adjust to the lower level of operating balances, and the funds rate became more volatile for a period of time. Consistent with the New York Fed's assessment of the impact of these changes, preliminary analysis indicated that the Desk did not follow the operating procedure closely during maintenance periods affected by these reserve requirement changes. ${ }^{9}$ Consequently, these maintenance periods were deleted to avoid biasing the results. Finally, there are days when some of the observations are missing because of incomplete records. These observations also have been deleted. The final number of daily observations is 3,176 .

Table 1 summarizes, by day of the maintenance period, whether the procedure suggested the Desk add or drain reserves and what the Desk actually did. The reserve maintenance period ends on every other Wednesday. This is called settlement Wednesday and is denoted by SW. There were four instances in the sample period when the maintenance period effectively ended on Tuesday because the normal reserve settlement day was a holiday. In these instances, the preceding Tuesday was designated SW because banks settled their reserve accounts on that day. ${ }^{10}$ Hence, all but four settlement days are Wednesdays. All other days in the maintenance period are recorded on their corresponding calendar day.

Table 1 shows that, for all days, the procedure indicated that reserves be added more often than drained. This is due in large part to the fact that the primary government security dealers, with whom the Desk conducts daily open market operations, prefer to sell rather than purchase securities from the Desk. Hence, the operating procedure is designed so that, more often than not, there is a need to add rather than drain reserves. It is also due to the fact that the currency grew at a fairly constant rate over most of this period. Hence, reserves needed to be added more often than drained to accommodate currency growth.

\footnotetext{
9 See Sternlight (1991).

${ }^{10}$ Reserve balances held on that day counted for two days.
} 


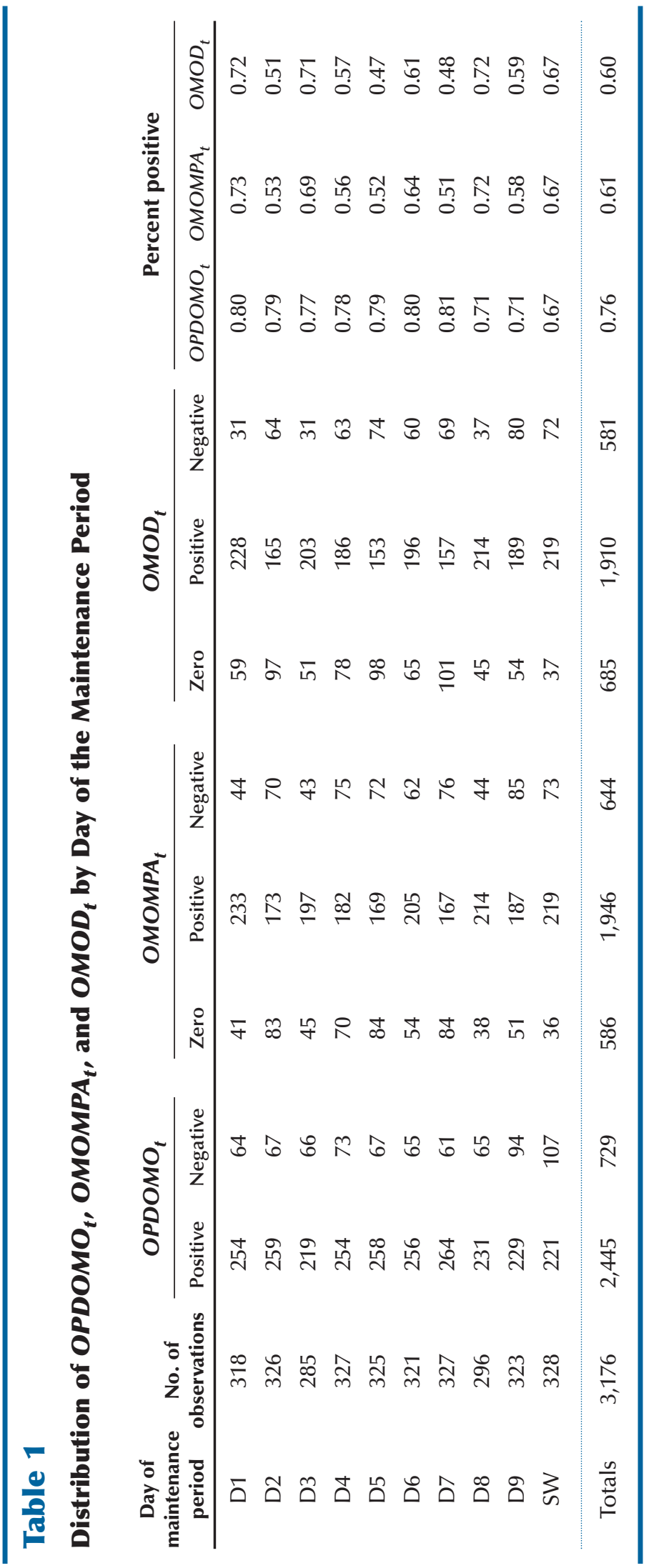


The need to add reserves is particularly acute on the first day of the maintenance period: Estimates of reserve demand and reserve supply are estimates of the maintenance period average; that is, they are daily estimates of the demand for or supply of reserves on average over the maintenance period. Consequently, the procedure automatically accounts for repurchase agreements (RPs) that were executed during previous maintenance periods but are scheduled to mature sometime during the current maintenance period.

Table 1 compares OPDOMO with two measures of actual daily open market operations, $O M O D_{t}$ and $O M O M P A_{t}$. OMOD $D_{t}$ is the net of open market purchases and sales of government securities on the day. This is likely what most people think of when discussing open market operations. In contrast, $O M O M P A_{t}$ reflects the effect of the net operation on the supply of reserves over the maintenance period. For example, assume that the Desk purchases exactly as much as it sold on the day but sold overnight and purchased with a multiple-day term. In this instance, $O M O D_{t}$ would be zero but $O M O M P A_{t}$ would be positive. $O M O M P A_{t}$ reflects the net effect of the day's open market operation on reserves over the maintenance period, while $O M O D_{t}$ indicates the net amount of purchases and sales on the day. Consequently, one measure may indicate a purchase and the other a sale. Indeed, there are 102 days when this occurred. There are another 102 days when $O M O D_{t}$ is zero but $O M O M P A_{t}$ is not. There are only three instances when the reverse is true, however. Despite these differences, these measures are highly correlated (0.75).

Both measures indicate that Desk actions frequently had no impact on the supply of reserves. On nearly 22 percent of the days $O M O D_{t}$ was zero, while on nearly 19 percent of the days $O M O M P A_{t}$ was zero. The decision not to affect the supply of reserves either on the day or over the maintenance period appears to be influenced, in part, by the magnitude of $O P D O M O_{t}$. OMOD $D_{t}$ and $O M O M P A_{t}$ are more likely to be zero when $O P D O M O_{t}$ is relatively small and are almost never zero when $O P D O M O_{t}$ is relatively large.

While the data in Table 1 suggest that the Desk follows the operating procedure relatively closely, it did not follow the procedure mechanically. The correlation between $O P D O M O_{t}$ and $O M O M P A_{t}$ is $0.61 .^{11}$ Figure 1 presents a scatter plot of these variables with $O P D O M O_{t}$ on the horizontal axis and $O M O M P A_{t}$ on the vertical axis. These data indicate that the Desk's actions were not exactly as prescribed by the operating procedure: They generally added less than indicated when the procedure called for adding reserves and drained less than indicated when the procedure called for draining reserves. This behavior is due in part to the fact that the Desk often does nothing when the procedure suggests a relatively small need to add or drain reserves.

The discrepancy is also due, in part, to the fact that the Desk underestimated reserve demand on average. The average forecast error is $\$ 0.07$ billion, with a standard deviation of $\$ 0.37$ billion. The forecast errors are slightly skewed upward, as the median is $\$ 0.06$ billion, and are highly serially correlated (0.83). ${ }^{12}$ Although the mean and median forecast errors are both significantly different from zero at the 5 percent significance level, they are small relative to the mean $(\$ 54.6$ billion) and median ( $\$ 56.8$ billion) levels of total reserves. Hence, the Desk did a good job of forecasting reserve demand.

\section{How Well Did the Desk Follow Its Operating Procedure?}

I estimate the following equation to formally investigate the extent to which the Desk followed its operating procedure and the extent to which the Desk responded to other factors in conducting daily open market operations:

$$
\mathrm{OMOMPA}_{t}-\mathrm{OPDOMO}_{t}=\alpha+\beta z_{t}+\varepsilon_{t},
$$

where $z_{t}$ denotes a vector of factors that might cause the Desk to deviate from its operating procedure and $\varepsilon_{t}$ denotes the effect of all factors not

\footnotetext{
${ }^{11}$ Because the operating procedure is directed at the quantity of reserves over the maintenance period, it is not surprising that the correlation between $O P D O M O_{t}$ and $O M O D_{t}$ is considerably lower, 0.46 .

${ }^{12}$ Daily total reserves are available only for the period January 2, 1986-December 31, 1996. These statistics are based on the official measures of required and excess reserves for the period.
} 


\section{Figure 1}

\section{Comparison of OPDOMO and OMOMPA, March 1, 1984-December 31, 1996}

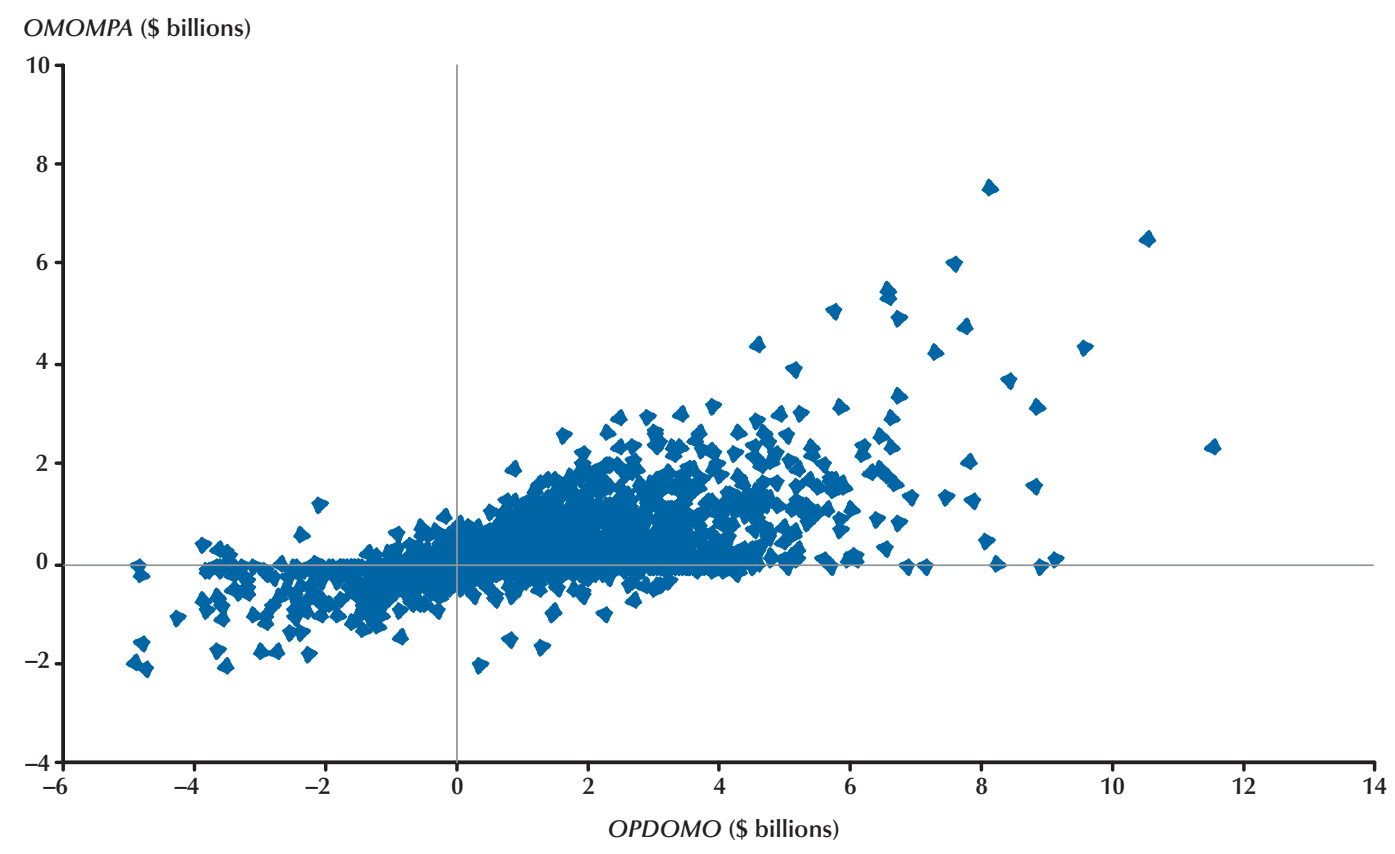

reflected in $z_{t}$. If the Desk followed the operating procedure perfectly, then $\alpha=\beta=\varepsilon_{t}=0$.

Factors That May Have Caused the Desk To Respond Differently. There are a number of factors that might cause the Desk to deviate from its operating procedure. For example, demand for reserves is determined by banks' reserve requirements over a two-week period ending on the Monday two days before settlement Wednesday. Hence, on the last two days of the maintenance period, the demand for reserves is perfectly interest inelastic. Because the demand for reserves is fixed on these days, the Desk might behave somewhat differently on these days. The Desk may also behave differently on various days of the year, such as the first and last days of the month, quarter, or year and particular days of the maintenance period. Indeed, Hamilton (1997), Thornton (2001a), Carpenter and Demiralp (2006), and Demiralp and Farley (2005) report statistically significant day-of-the-maintenance-period and day-of-the-year effects for various aspects of open market operations. These possibilities are investigated by including dummy variables for the beginning of month, bom; end of month, eom; beginning of quarter, boq; end of quarter, eoq; beginning of year, boy; end of year, eoy; and for each day of the maintenance period.

Table 1 suggests that the Desk may follow the operating procedure more closely when it indicates that reserves should be added than when it indicates that reserves should be drained. To investigate this formally, the day-of-the-maintenance-period dummy variables are partitioned according to whether $O P D O M O_{t}$ is positive or negative.

Because of the difficulty in estimating reserve demand, the Desk might look to the recent behavior of the funds rate or other signals of current market conditions in conducting daily open market operations. The Desk takes a reading on the funds rate just prior to the morning call. The morning call is a telephone conference among the staffs of the Board of Governors, the Desk, 
and one of Federal Reserve Bank presidents. All parties have access to the reserve projections, and the Desk outlines its intentions for that day's open market operation. One element of the call is where the funds rate is trading "at the time of the call." There are no transcripts of these calls; however, Thornton (2006) documents that the rate at the time of the call was used as a check on the Desk's estimates of reserve demand. Hence, it is reasonable to conjecture that the Desk might respond differently depending on the difference between the funds rate at the time of the call and the funds rate target, call - fftar.

It seems likely that the Desk does not follow its procedure on days when the funds rate target is adjusted. Conceptually, the Desk's operating procedure is conditional on the funds rate target. Consequently, a change in the target should have an effect on the estimate of the quantity of reserves demanded; however, it may be difficult to estimate the effect of a target change on the quantity of reserves demanded. Moreover, because the demand for reserves is fixed on the last two days of the maintenance period, exactly how the Desk would behave relative to the operating procedure on those days is uncertain.

Finally, Hamilton (1997) has argued that the Fed responds to forecast misses in one of the components of $v_{t}$-the Treasury's balance with the Fed. Specifically, Hamilton suggests that if the Treasury's balance were $\$ 400$ million lower than expected, the Desk would add $x$ for each of the $n$ remaining days in the maintenance period to make up for that day's error in forecasting the Treasury's balance. If the forecast errors are serially correlated, this information could be used in making today's estimate of $F_{t}$. To my knowledge the forecast errors were never saved and analyzed. Consequently, it seems unlikely that the Desk engaged in the explicit error-correction behavior Hamilton describes. In any event, if it did, it should have also responded to the previous day's difference between actual bank borrowing and the IBA because borrowing is highly serially correlated and the $I B A$ was changed relatively infrequently.
Empirical Results. Equation 5 was estimated accounting for the factors noted above. Estimates of $v_{t}$ are those used by Carpenter and Demiralp (2006) and were provided by the authors. These data are available only beginning in January 1986; consequently, the estimation period is January 2, 1986, through December 31, 1996. There is only an estimate of the net forecast error for all components. There is a separate estimate for the Treasury's balance at the Fed. Hence, the BOG's forecast error for Treasury balances on the previous day $\left(F E(T b a l)_{t-1}\right)$ is also included. With this addition, the coefficient on $v_{t-1}$ should reflect the explicit error correction behavior of the Desk for the remaining factors, whereas the coefficient on $F E(T b a l)_{t-1}$ reflects the explicit error-correction behavior with respect to Treasury balance forecast errors.

Finally, at its first meeting in 1994, the FOMC began announcing policy actions upon taking them. Because of this, and because banks began implementing deposit sweep programs that reduced the demand for reserves at about the same time, estimates of (5) are presented for periods both before and after 1994. Also, the announcement came later in the day, after the Desk had conducted that day's open market operations. Consequently, for analyses of the effect of changes in the funds rate target on Desk operations, the changes in the funds rate target are aligned to the first day that the Desk could have responded to the FOMC's action.

The estimates are presented in Table 2. The equation was estimated using a Newey-West estimator of the covariance matrix. The coefficient estimates are reported in one column, and the significance level associated with the null hypothesis that the coefficient is zero is reported in the adjacent column. Although a formal test of the null hypothesis of temporal stability is easily rejected, the results for the two periods are remarkably similar. Consistent with Table 1, during both periods the Desk adds less reserves than the procedure indicates should be added and drains less reserves than the procedure indicates should be drained. Moreover, during both periods, the absolute values of the coefficients on the day-ofthe-maintenance-period dummy variables decline 
Table 2

The Desk's Use of the Operating Procedure: February 2, 1986-December 31, 1996

\begin{tabular}{|c|c|c|c|c|}
\hline \multirow[b]{2}{*}{ Variable } & \multicolumn{2}{|c|}{ Pre-1994 } & \multicolumn{2}{|c|}{ Post-1994 } \\
\hline & Coefficient & Significance level & Coefficient & Significance level \\
\hline bom & 0.272 & 0.014 & 0.313 & 0.051 \\
\hline eom & 0.277 & 0.050 & 0.182 & 0.242 \\
\hline$b o q$ & -0.198 & 0.365 & -0.308 & 0.446 \\
\hline eoq & -0.150 & 0.533 & -0.504 & 0.188 \\
\hline boy & -0.401 & 0.229 & 0.314 & 0.447 \\
\hline eoy & -0.244 & 0.559 & 0.538 & 0.214 \\
\hline 1st Thursday positive & -2.135 & 0.000 & -3.087 & 0.000 \\
\hline 1st Friday positive & -1.943 & 0.000 & -2.905 & 0.000 \\
\hline 1st Monday positive & -1.590 & 0.000 & -2.477 & 0.000 \\
\hline 1st Tuesday positive & -1.503 & 0.000 & -2.212 & 0.000 \\
\hline 1st Wednesday positive & -1.434 & 0.000 & -1.941 & 0.000 \\
\hline 2nd Thursday positive & -0.923 & 0.000 & -1.188 & 0.000 \\
\hline 2nd Friday positive & -0.837 & 0.000 & -0.943 & 0.000 \\
\hline 2nd Monday positive & -0.345 & 0.000 & -0.365 & 0.000 \\
\hline 2nd Tuesday positive & -0.297 & 0.000 & -0.329 & 0.000 \\
\hline SW positive & -0.223 & 0.000 & -0.148 & 0.002 \\
\hline 1st Thursday negative & 1.532 & 0.000 & 1.576 & 0.000 \\
\hline 1st Friday negative & 1.501 & 0.000 & 1.118 & 0.000 \\
\hline 1st Monday negative & 1.081 & 0.000 & 1.007 & 0.000 \\
\hline 1st Tuesday negative & 0.904 & 0.000 & 1.096 & 0.001 \\
\hline 1st Wednesday negative & 0.757 & 0.000 & 1.103 & 0.001 \\
\hline 2nd Thursday negative & 0.609 & 0.000 & 0.360 & 0.008 \\
\hline 2nd Friday negative & 0.374 & 0.000 & 0.330 & 0.041 \\
\hline 2nd Monday negative & 0.187 & 0.002 & 0.182 & 0.249 \\
\hline 2nd Tuesday negative & 0.208 & 0.000 & 0.149 & 0.087 \\
\hline SW negative & 0.198 & 0.000 & 0.194 & 0.002 \\
\hline$\Delta$ fftar 2nd Tuesday and SW & -0.393 & 0.446 & -0.084 & 0.786 \\
\hline$\Delta f f t a r$ all other days & -1.166 & 0.043 & 1.575 & 0.113 \\
\hline $\mathrm{Call}_{t}-\mathrm{fftar}_{t}$ & 0.237 & 0.094 & 0.532 & 0.028 \\
\hline$v_{t-1}$ & -0.016 & 0.585 & 0.000 & 0.996 \\
\hline$F E(T b a l)_{t-1}$ & -0.016 & 0.080 & 0.014 & 0.823 \\
\hline$B R_{t-1}-I B A_{t-1}$ & -0.016 & 0.124 & -0.249 & 0.313 \\
\hline No. of observations & 1,680 & - & 743 & - \\
\hline Standard error & 0.972 & - & 0.956 & - \\
\hline $\bar{R}^{2}$ & 0.515 & - & 0.635 & - \\
\hline
\end{tabular}


nearly monotonically from the first to the last day of the maintenance period. Moreover, the Desk does not systematically deviate from its operating procedure at the beginning or end of the quarter, or year, during either period. The Desk's response on the first and last days of the month are similar during both periods; however, the response at the end of the month is clearly not statistically significant for the post-1994 period.

There are some differences in the Desk's response to other information. Specifically, during the pre-1994 period the Desk deviated from the operating procedure on days when the funds rate was changed-except on the last two days of the maintenance period, when reserve demand was fixed. In contrast, after 1994, there is no statistically significant deviation from the operating procedure when the funds rate target is changed. This finding is consistent with Taylor (2001) and Thornton (2001a). There was no attempt to alter the supply of reserves immediately after the FOMC began the practice of announcing policy actions. ${ }^{13}$

The estimates also suggest that the Desk relied more on the behavior of the funds rate at the time of the call after 1994 than it did before 1994. The point estimate indicates that on average the Desk added about $\$ 0.5$ billion more than the operating procedure suggested for every percentage point deviation of the funds rate from the target at the time of the call. Although the estimate is small given the size of the daily market for federal funds, it nevertheless indicates that the Desk behaved in a manner consistent with keeping the funds rate close to the target after 1994.

Finally, there is no evidence of explicit error correction by the Desk during either period. The coefficient on $v_{t-1}$ is negative but not statistically significant at the 5 percent level for either period. The coefficient on $F E(\text { Tbal })_{t-1}$ is negative for the pre-1994 period, but again not statistically significant. Likewise, the coefficients on $B R_{t-1}-I B A_{t-1}$ are negative but not significantly different from zero in either period.

\footnotetext{
${ }^{13}$ I do not say "announcing changes in the funds rate target" because the FOMC had not formally acknowledged that it was targeting the funds rate at this time. See Thornton (2005) for details.
}

\section{THE LIQUIDITY EFFECT}

The liquidity effect-the decline in nominal interest rates associated with an exogenous, central bank-engineered increase in the monetary base-has received relatively little empirical support historically (e.g., Pagan and Robertson, 1995; and Thornton, 1988; 2001a,b; 2006). The Desk's open market data provide a unique opportunity to investigate the extent to which Fed actions influence the federal funds rate. If the Fed acts to change the equilibrium funds rate through open market operations, there should be a marked change in open market operations on days when the funds rate target is changed.

The estimates reported in Table 2 suggest that the Desk behaved in a manner consistent with the liquidity effect prior to 1994, but not after. Specifically, the Desk added about $\$ 0.3$ billion fewer reserves than the procedure suggested when the funds rate target was increased by 25 basis points before 1994. ${ }^{14}$ This estimate suggests that the demand for federal funds is very interest inelastic: That is, a very small exogenous change in reserves generates a relatively large change in the funds rate. If the demand for reserves is this inelastic, however, one has to wonder why the liquidity effect has been so elusive. Hence, the remainder of this section investigates the liquidity effect in a variety of ways.

\section{Changes in Estimates of Reserve Demand}

Consistent with the conventional view, the results in Table 2 suggest that, before 1994 but not after, the Desk drained more reserves than the operating procedure suggested when the funds rate target was increased and added more when

\footnotetext{
${ }^{14}$ Demiralp and Jorda (2002) investigate the liquidity effect using a similar methodology. Specifically, they estimate the response of open market transactions of various types to surprise changes in the funds rate target for a subperiod of the period April 25, 1984, through August 14, 2000. They find evidence that they interpret as being "broadly consistent with the traditional liquidity effect" prior to 1994 but not after. Recently, however, de Jong and Herrera (2004) have re-evaluated Demiralp and Jorda's work. Consistent with the findings presented here, they find no evidence consistent with a liquidity effect over the entire sample period, but find evidence consistent with a liquidity effect for a sub-period after August 18, 1998, when lagged reserve accounting was reintroduced.
} 
Table 3

\section{The Desk's Behavior When the Target Is Changed}

\begin{tabular}{lcc} 
& $\begin{array}{c}\mathbf{9 0} \% \text { Coverage } \\
\text { interval }\end{array}$ & Sample results \\
\hline Mean & & \\
43 & -0.397 to -1.079 & -0.454 \\
45 & -0.414 to -1.081 & -0.056 \\
Median & & \\
43 & -0.168 to -0.727 & -0.490 \\
45 & -0.171 to -0.733 & -0.231 \\
Standard deviation & & \\
43 & 0.990 to 1.776 & 1.436 \\
45 & 1.006 to 1.770 & 1.234 \\
\hline
\end{tabular}

the target was reduced. The size of the estimated coefficient for the pre-1994 period is relatively small, however. A potential explanation for the small coefficient is that, because the Desk's estimates of reserve demand are conditional on the funds rate target, the Desk reduces its estimate of the quantity of reserves demanded on days when the target is increased and increases its estimate on days when the target is reduced. There were 88 changes in the funds rate target during the sample period (43 increases and 45 decreases). Of these, 78 occurred prior to 1994 and 10 after. Figures 2 and 3 present the revisions to reserve demand when the funds rate target was increased or decreased, respectively. These data are not consistent with the idea that the Desk revises its estimate of reserve demand systematically in response to a change in the target. Figure 2 shows that there were only six occasions when reserve demand was revised down by $\$ 0.5$ billion or more when the target was increased, whereas there were four days when it was revised up by a corresponding amount. Likewise, Figure 3 shows that estimates of reserve demand were not systematically revised up in response to a decrease in the target. Indeed, most often the estimates were essentially unrevised, despite the change in the target. Hence, the relatively small estimated coefficient in Table 2 is not the consequence of systematic revisions of reserve demand.

\section{The Desk's Behavior When the Funds Rate Target Is Changed}

The results in the previous section indicate that the Desk deviated significantly from its operating procedure when the target was changed, at least prior to 1994. This result is investigated more fully in Figures 4 and 5, which show scatter plots of $O P D O M O$ vs. OMOMPA on days when the funds rate target was decreased and increased, respectively. If the Desk causes the funds rate to fall, there should be many more observations above the 45-degree line than below in Figure 4. This is not the case, however. Likewise, if the Desk causes the funds rate to rise, there should be many more observations below the 45-degree line than above in Figure 5. Although this is the case, as I have already noted, the procedure was skewed toward adding rather than draining reserves. Moreover, Figure 1 shows that the Desk generally added significantly less than the procedure suggested on all days when the procedure indicated reserves should be added. Consequently, it is not clear whether Figure 5 represent a significant change in the Desk's behavior on days when the target was increased.

To investigate whether the Desk behaved significantly differently when the funds rate target was changed, 10,000 samples (sizes 43 and 45) were obtained by bootstrapping the 3,088 observations of OMOMPA - OPDOMO on days when the target was not changed. Table 3 reports the 90 percent coverage intervals for the mean, median, and standard deviation of these samples along with the same sample statistics for days when the funds rate target was changed. The results suggest that the Desk did not change its behavior significantly when the funds rate target was increased. Five of the six sample statistics are well within the corresponding 90 percent coverage intervals. The sample mean of the 45 days when the target was decreased lies outside of the 90 percent coverage interval, suggesting that the Desk added significantly more reserves on average than the operating procedure indicated when the target was decreased. Because the distributions of $O M O M P A-O P D O M O$ are skewed, the median is a better measure of central tendency. The sample 
Figure 2

Revisions to Reserve Demand When the Target Was Increased

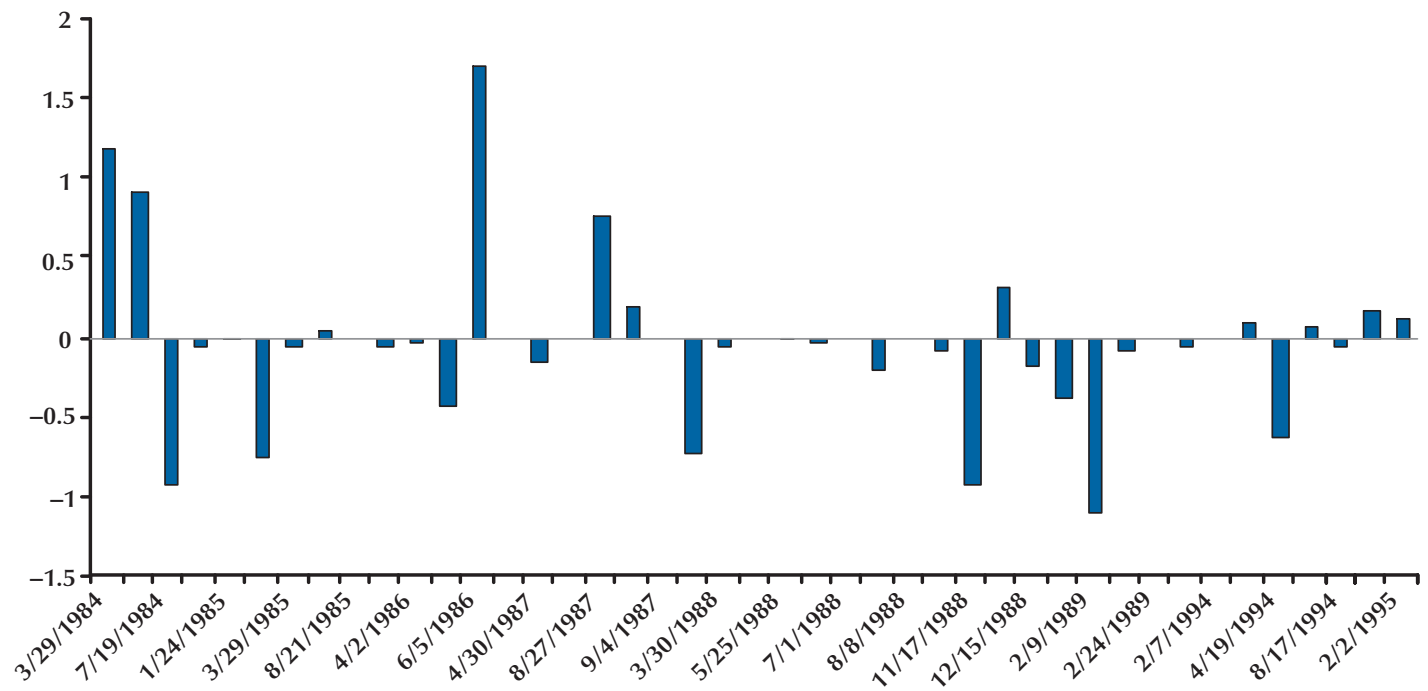

\section{Figure 3}

Revisions to Reserve Demand When the Target Was Decreased

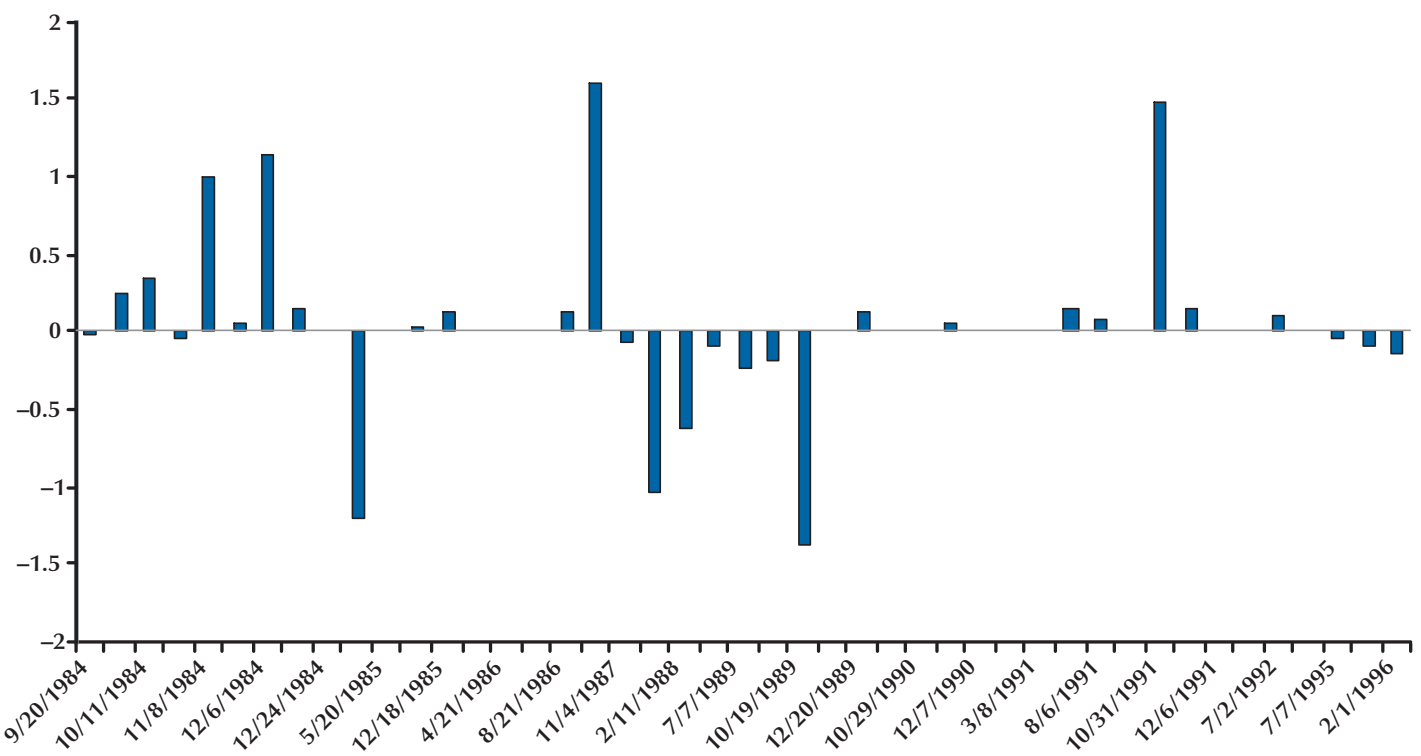


Thornton

Figure 4

OPDOMO and OMOMPA on Days When the Target Was Decreased

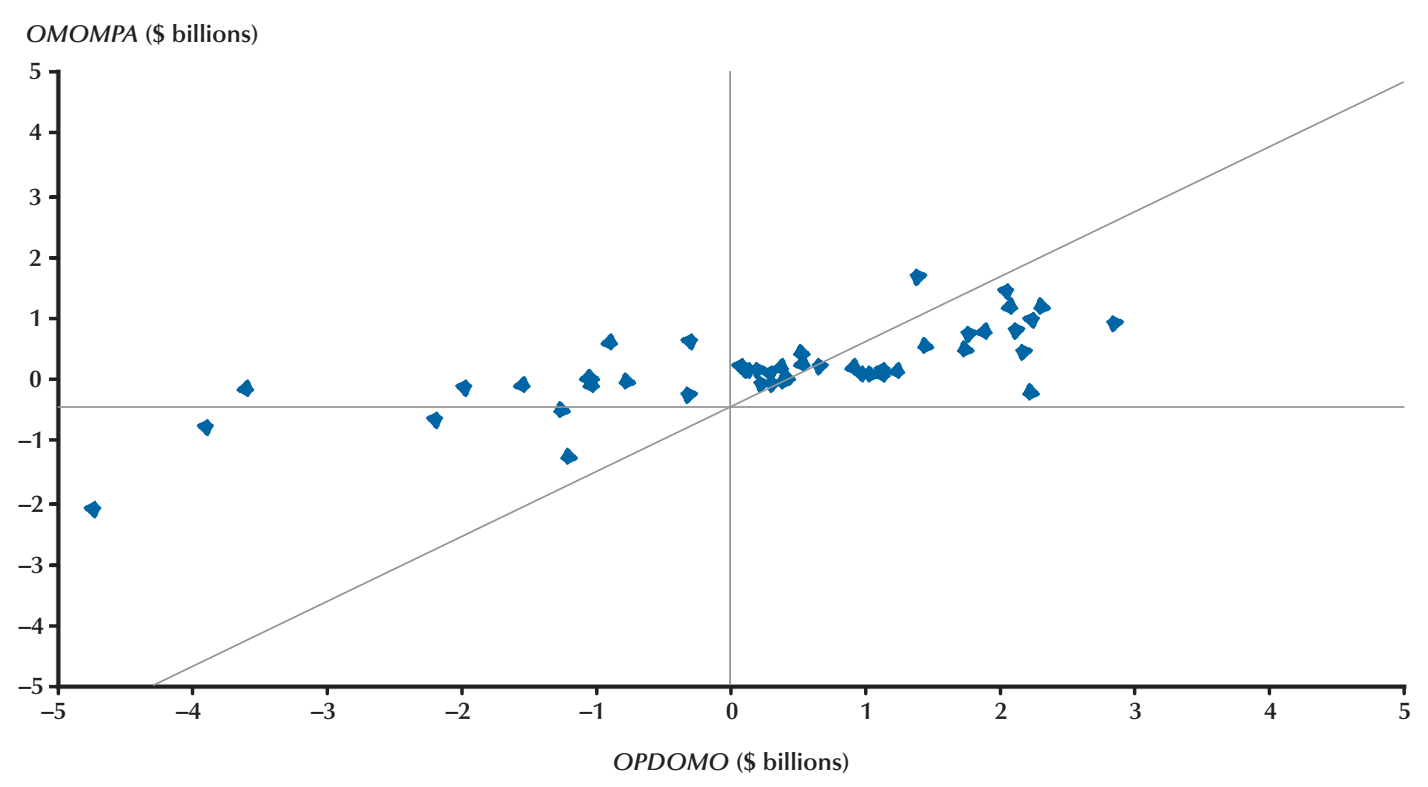

Figure 5

OPDOMO and OMOMPA on Days When the Target Was Increased

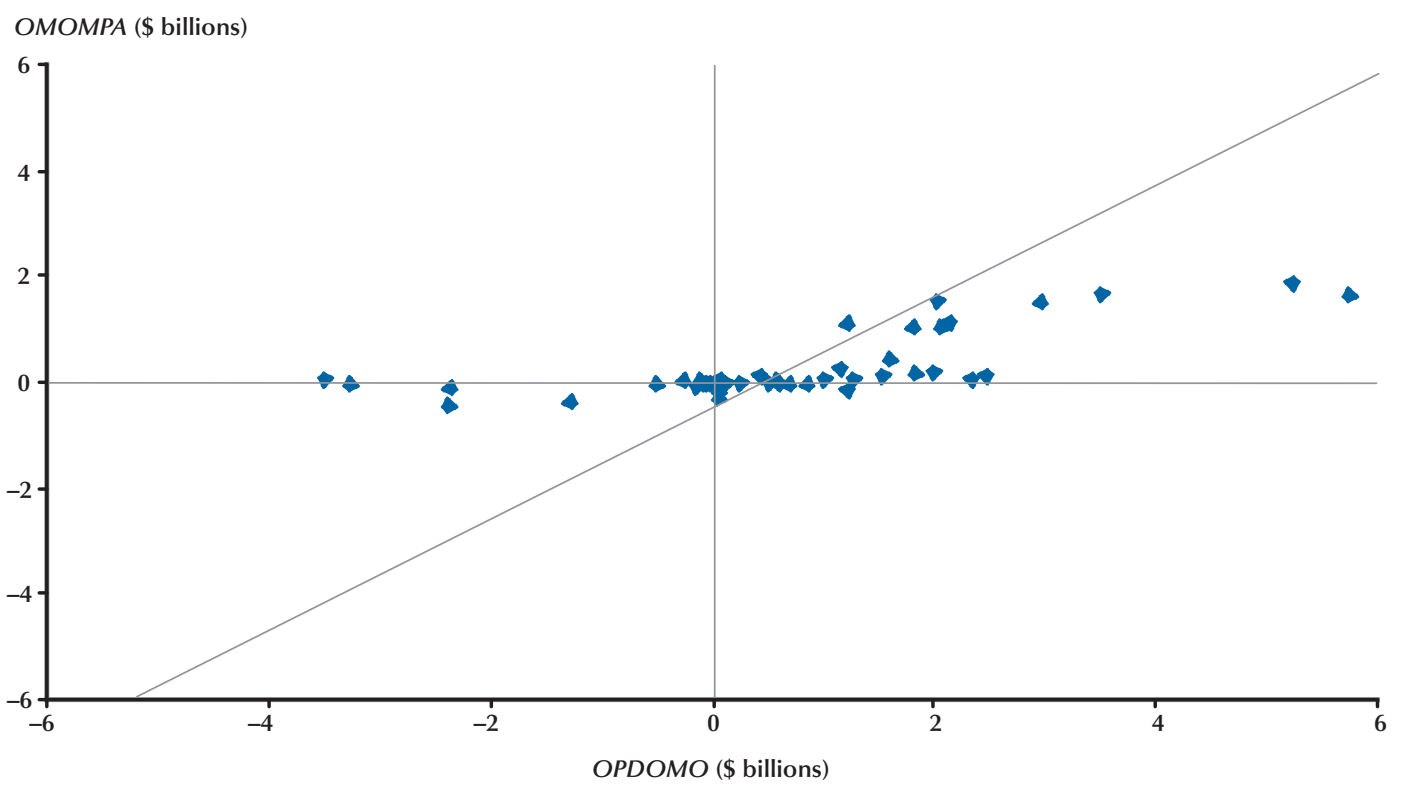

560

NOVEMBER/DECEMBER 2007

FEDERAL RESERVE BANK OF ST. LOUIS REVIEW 
statistic for the median is well within the coverage interval, suggesting that the Desk did not behave differently when the target was decreased. Hence, there is weak evidence that suggests the Desk attempted to engineer decreases in the funds rate.

\section{Implementing a Target Change Over Time}

It might be the case that the Desk does not take all the operations necessary to change the funds rate on the day the target is changed. Instead, the Desk may add or drain reserves over several days to bring about the change in reserves necessary to sustain the funds rate at the new target level (e.g., Taylor, 2001).

This possibility is investigated by comparing the five-day averages of OMOMPA - OPDOMO for five days before each target change and for the day of the target change and four days after the change. The five-day averages are plotted in Figures 6 and 7 for increases and decreases in the funds rate target, respectively. ${ }^{15}$ If the Desk pursued the increase in the funds rate, there should be more observations below the 45-degree line than above in Figure 6. Similarly, if the Desk pursued the decrease in the funds rate, there should be more observations above the 45 -degree line than below in Figure 7. This is not the case. In both instances, the number of observations above and below the 45-degree line is nearly equal. Moreover, simple tests of the equality of the means, medians, and variances of the distributions before and after target changes cannot reject the null hypothesis of equality at even the 10 percent significance level for either positive or negative target changes. Consequently, there is no evidence that the Desk implemented target changes over a period of five days. It is important to note that the conclusion is the same for both increases and decreases in the target. Hence, if the Desk engineered increases in the funds rate target, it completed the operations necessary to effect these changes quickly.

\footnotetext{
15 There were 14 occasions ( 8 for positive and 6 for negative changes in the target) when there were fewer than five days between successive target changes. These changes were deleted so as not to bias the results.
}

\section{Estimating the Liquidity Effect Directly}

The conventional way to estimate the liquidity effect is to regress changes in the interest rate on a variable that represents an exogenous change in reserves or monetary policy. Hamilton (1997) used this approach and found evidence of a statistically significant liquidity effect of exogenous changes in reserves on the federal funds rate. His measure of a supply shock was his estimate of the forecast error the Desk makes in forecasting the Treasury's balance with the Fed. Hamilton found the liquidity effect to be statistically significant, but only on settlement Wednesdays. Thornton (2001a) notes three problems with this analysis. First, the slope of the reserve demand function (and, therefore, the liquidity effect) cannot be estimated on settlement Wednesdays because of the two-day lag in the Fed's reserve accounting system. Second, what matters on the last day of the maintenance period is the imbalance of reserve supply and demand on average over the maintenance period. Because a one-day error in forecasting the Treasury's balance contributes only one-fourteenth of the average error, it would take a very large shock to the Treasury's balance on the last day of the maintenance period to generate a large maintenance-period-average reserve imbalance. Finally, Thornton notes that Hamilton used an estimate of the Desk's forecast error, not the actual forecast error. ${ }^{16}$ Thornton (2001a) goes on to show that Hamilton's settlement-Wednesday liquidity effect was idiosyncratic to his sample period, and, even during Hamilton's sample period, it is attributable to just six observations when the funds rate changed by a large amount on settlement Wednesdays.

Carpenter and Demiralp (2006) attempt to overcome some of the data shortcomings of Hamilton's analysis by using a more comprehensive measure of a reserve supply shock. Specifically, they use an estimate of $v_{t}$ based on the Board of Governors' estimate of $F_{t} \cdot{ }^{17}$ They find a

\footnotetext{
${ }^{16}$ See Thornton (2004) for analysis of the Desk's forecast error and comparison of those errors with Hamilton's estimates.

17 The Board kindly provided me with these forecast errors, which cover the period January 2, 1986-June 30, 2000, for the Board of Governors' estimates and December 23, 1993-June 30, 2000, for the New York Fed's estimates.
} 
Figure 6

Scatter Plot of OPDOMO - OMOMPA Five Days Before and Five Days After Target Increases

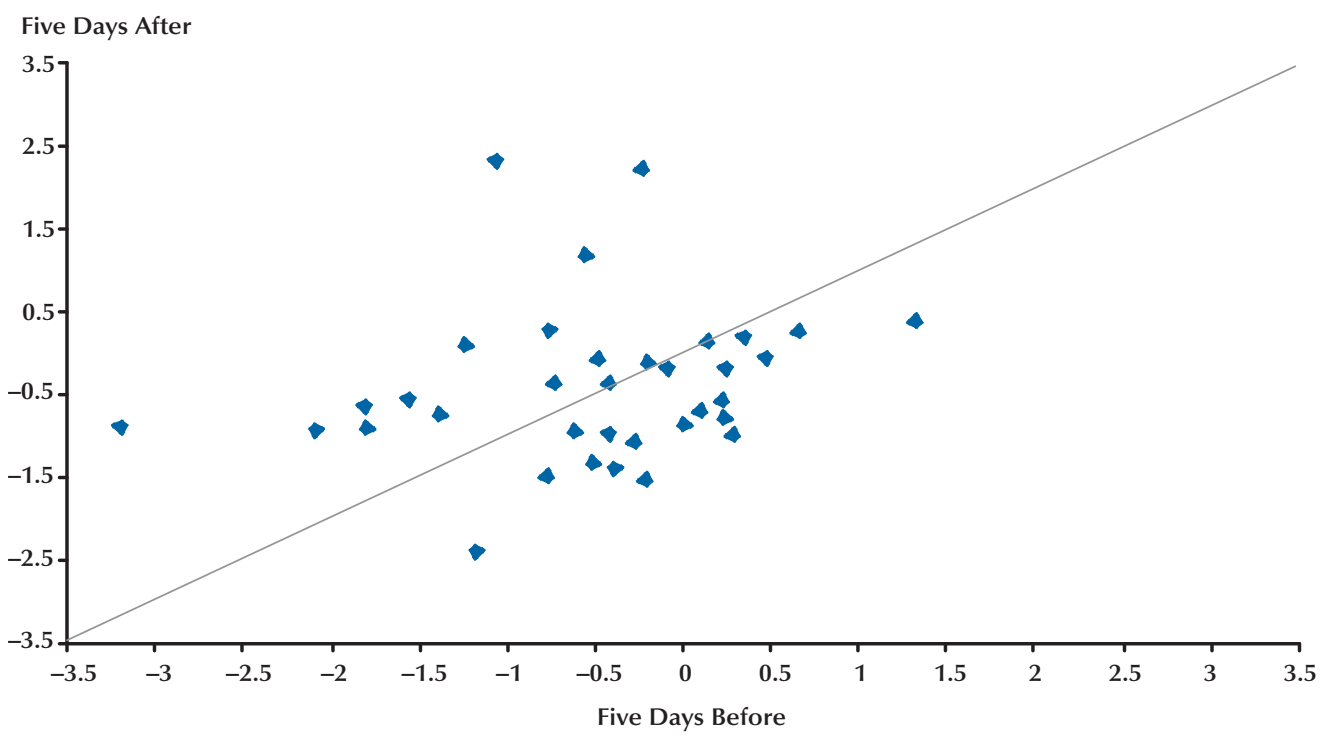

Figure 7

Scatter Plot of OPDOMO - OMOMPA Five Days Before and Five Days After Target Decreases

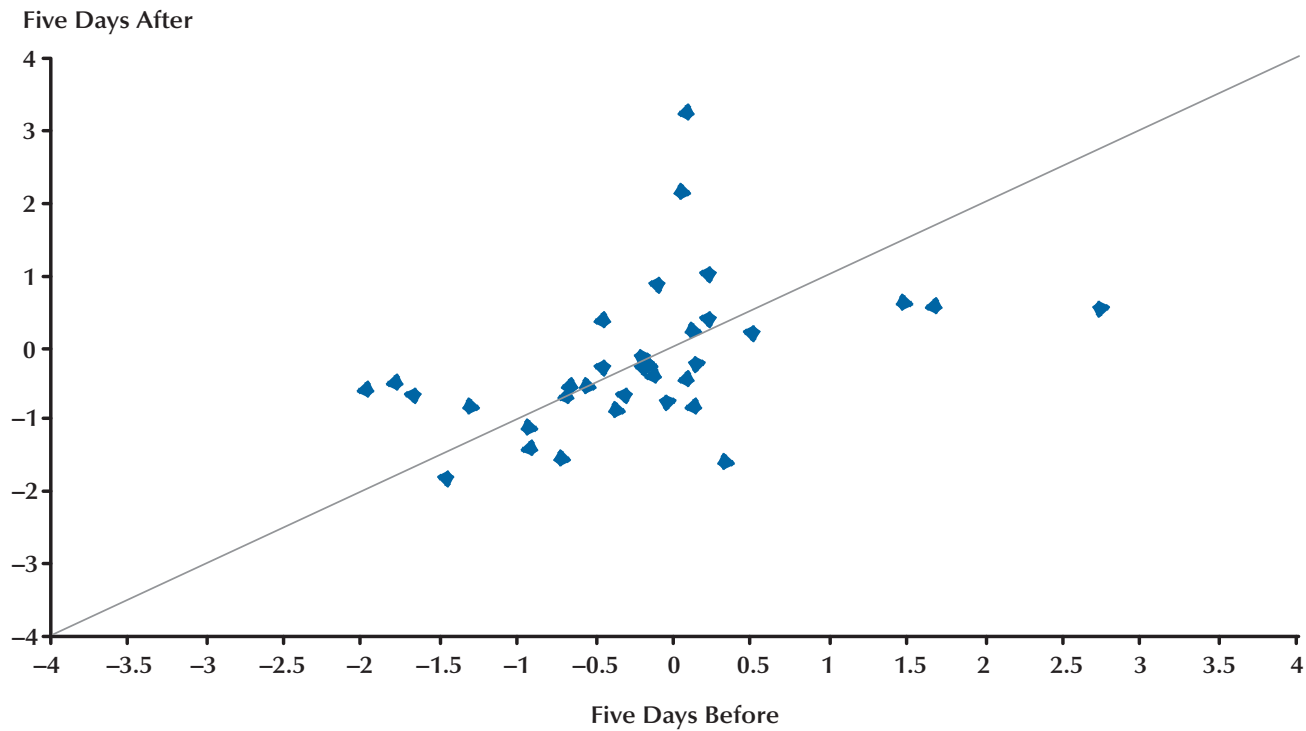




\section{Figure 8}

\section{Scatter Plot of $\mathrm{ff}$ - fftar and Errors in Forecasting Autonomous Factors (January 2, 1986-December 31,1996)}

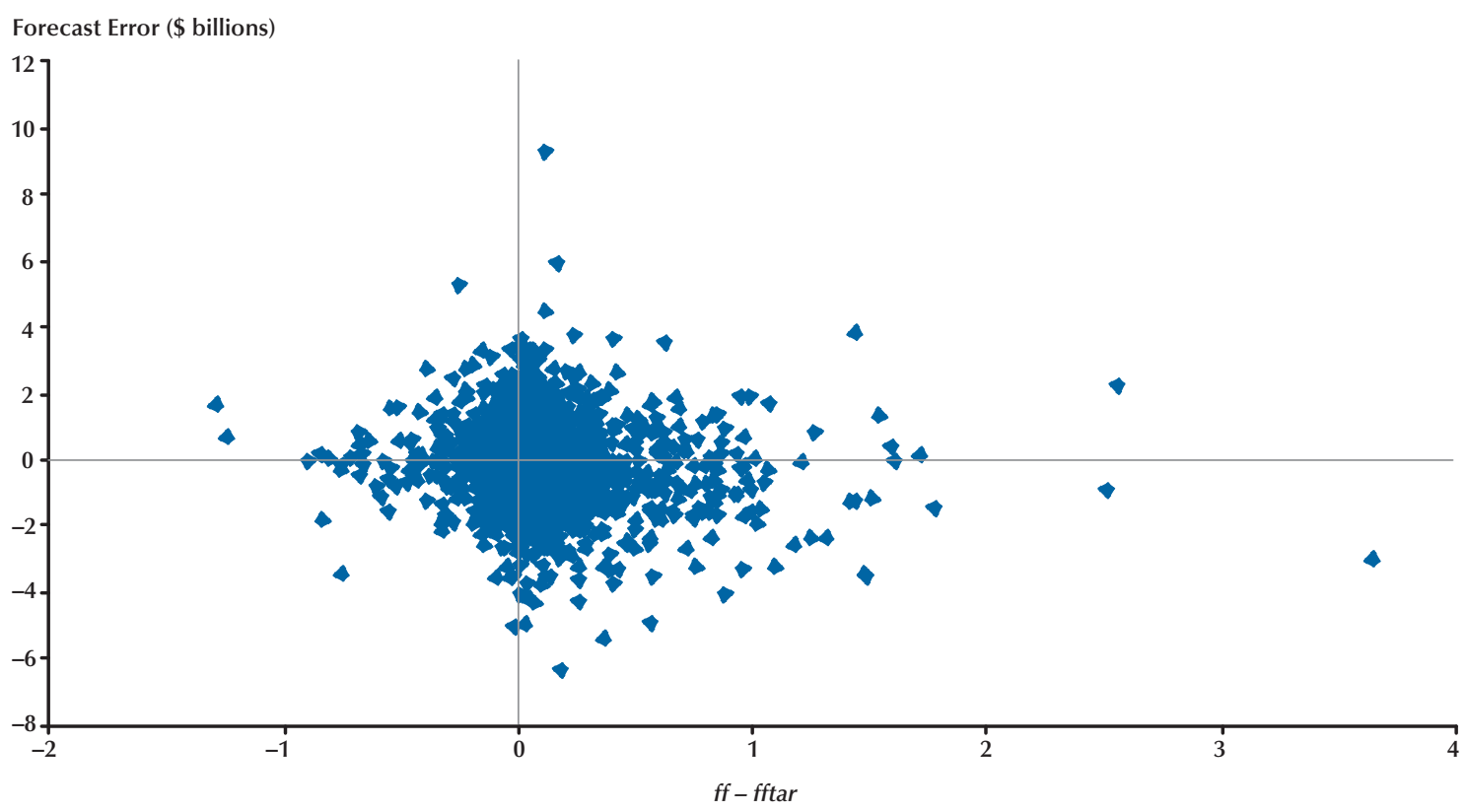

statistically significant liquidity effect on six of the ten days during the maintenance period over the period May 18, 1989, through January 30, 2004. As with Hamilton's findings, the estimated liquidity effect is largest on settlement Wednesdays when, contrary to Carpenter and Demiralp's assertion, the slope of the demand for reserves cannot be estimated. ${ }^{18}$

The effects of shocks to reserves on the funds rate is investigated here using Carpenter and Demiralp's data. Figure 8 presents a scatter plot of the $(f f-f f t a r)_{t}$ and the BOG's estimate of $v_{t}$ over the period January 2, 1986, through December 31, 1996. Days when $v_{t}$ was not available and the last two days of 1986, when $(f f-f f t a r)_{t}$ was more than 8 percentage points, are deleted, leaving 2,676 daily observations. Although not obvious from Figure 8, there is a weak negative relationship

${ }^{18}$ The slope of the demand curve cannot be estimated during any of the days of the maintenance period after August 1998, when the Fed returned to lagged reserve accounting. between $v_{t}$ and $(f f-f f t a r)_{t}$. The correlation is -0.124. Carpenter and Demiralp (2006) suggest that the relationship between supply shocks and the funds rate is nonlinear, finding that their statistically significant liquidity effect is due to large supply shocks ( $\geq \$ 1$ billion). Hence, the relatively low correlation could be due to the fact that most often supply shocks are relatively small. There is some evidence of this. When only days for which the absolute value of the supply shock is greater than $\$ 2$ billion (180 observations) are considered, the correlation nearly doubles to -0.215 . Nevertheless, even for large reserve supply shocks the relationship between reserve supply shocks and the funds rate appears weak.

I investigate this possibility further: Table 4 presents the results for a regression of $(f f-f f t a r)_{t}$ on day-of-the-year and day-of-the-maintenanceperiod dummy variables, (OMOMPA - OPDOMO $)_{t}$, and $v_{t}$ over the period January 2, 1986December 31, 1996. One might expect that, as with shocks to reserve supply, if the Desk adds 
Table 4

Estimate of $\mathrm{ff}_{t}-$ fftar $_{t}$, February 2, 1986-December 31, 1996

\begin{tabular}{|c|c|c|c|c|}
\hline Variable & Coefficient & Significance level & Coefficient & Significance level \\
\hline $\lg$ & - & - & 0.492 & 0.000 \\
\hline med & - & - & 0.379 & 0.000 \\
\hline$s m$ & - & - & 0.361 & 0.000 \\
\hline eom & 0.165 & 0.000 & 0.160 & 0.000 \\
\hline bom & 0.084 & 0.003 & 0.077 & 0.006 \\
\hline eoq & 0.287 & 0.001 & 0.283 & 0.002 \\
\hline$b o q$ & 0.093 & 0.326 & 0.099 & 0.278 \\
\hline eoy & 0.178 & 0.803 & 0.161 & 0.818 \\
\hline boy & 0.253 & 0.027 & 0.200 & 0.087 \\
\hline 1st Thursday & 0.106 & 0.000 & -0.266 & 0.000 \\
\hline 1st Friday & -0.013 & 0.252 & -0.376 & 0.000 \\
\hline 1st Monday & 0.080 & 0.000 & -0.289 & 0.000 \\
\hline 1st Tuesday & 0.040 & 0.000 & -0.331 & 0.000 \\
\hline 1st Wednesday & 0.000 & 0.964 & -0.370 & 0.000 \\
\hline 2nd Thursday & 0.013 & 0.244 & -0.358 & 0.000 \\
\hline 2nd Friday & -0.069 & 0.000 & -0.439 & 0.000 \\
\hline 2nd Monday & 0.080 & 0.000 & -0.292 & 0.000 \\
\hline 2nd Tuesday & 0.045 & 0.237 & -0.330 & 0.000 \\
\hline SW & 0.245 & 0.000 & -0.131 & 0.000 \\
\hline$(O M O M P A-O P D O M O)_{t}^{\Delta f f t a r}$ & -0.058 & 0.021 & -0.025 & 0.106 \\
\hline$(O M O M P A-O P D O M O)_{t}^{N o \Delta f f t a r}$ & -0.002 & 0.673 & 0.000 & 0.926 \\
\hline$v_{t}^{\Delta f f t a r}$ & -0.077 & 0.012 & - & - \\
\hline$v_{t}^{\text {No } \Delta f f t a r}$ & -0.032 & 0.005 & - & - \\
\hline$v_{t}^{l, \Delta f f t a r}$ & - & - & -0.102 & 0.020 \\
\hline$v_{t}^{l, N o \Delta f f t a r}$ & - & - & -0.045 & 0.031 \\
\hline$v_{t}^{m, \Delta f f t a r}$ & - & - & -0.083 & 0.055 \\
\hline$v_{t}^{m, \text { No } \Delta f f t a r}$ & - & - & -0.010 & 0.255 \\
\hline$v_{t}^{s, \Delta f f t a r}$ & - & - & 0.008 & 0.847 \\
\hline$v_{t}^{s, \text { No } \Delta f f t a r}$ & - & - & -0.034 & 0.076 \\
\hline No. of observations & 2,678 & - & 2,678 & - \\
\hline Standard error & 0.344 & - & 0.342 & - \\
\hline $\bar{R}^{2}$ & 0.102 & - & 0.111 & - \\
\hline
\end{tabular}


more reserves than the operating procedure indicates, the funds rate might fall, and vice versa. Given the previous results, (OMOMPA-OPDOMO) and $v_{t}$ are partitioned into days when the funds rate target was and was not changed. Consistent with Carpenter and Demiralp's finding, there is a negative and statistically significant relationship between $(f f-f f t a r)_{t}$ and $v_{t}$. Surprisingly, the absolute value of the estimate is nearly twice as large on days when the funds rate target was changed than when it was not. ${ }^{19}$

The results also suggest that the funds rate will decline if the Desk adds or drains more reserves than the operating procedure indicates is necessary. The coefficients are not statistically significant, however.

Following up on Carpenter and Demiralp's finding of non-linearity in the effect of supply shocks on the funds rate, I partition $v_{t}$ into days when the corresponding shocks are large $(l \geq \$ 2$ billion), medium ( $m>\$ 1$ billion but $<\$ 2$ billion), and small ( $s \leq \$ 1$ billion). To guarantee that the effect is due to non-linearity and not to an intercept shift, I include dummy variables for each of these partitions. The estimates, also presented in Table 4, confirm Carpenter and Demiralp's finding. ${ }^{20}$ Specifically, although the effect of $v_{t}$ on the funds rate is nearly always negative, it is statistically significant only for large supply shocks. Moreover, it is only on days when the target is not changed. The coefficient is larger for days when the target was changed, but not statistically significant at the 5 percent level. It is important to note that it takes a relatively large supply shock to have a statistically significant impact on the funds rate. Consequently, in contrast with the implications of the estimates from Table 2, these estimates suggest that the demand for reserves is relatively interest elastic. As noted above, shocks this large are relatively rare events. However, it is worth noting that when $v_{t}$ is partitioned by size,

\footnotetext{
19 The results are very similar if the sample ends on December 31, 1993; hence, the results for the shorter sample are not presented here.

${ }^{20}$ The equation was also estimated to allow for corresponding shifts in the intercept. The qualitative results were unchanged, so only the results that do not include corresponding shifts in the intercept are presented here.
}

with the exception of settlement Wednesday, day-of-the-maintenance-period differences in the behavior of the funds rate are significantly reduced and become statistically significant. Hence, there appears to be some relationship between large supply shocks and days of the maintenance period.

There are two reasons these findings do not support Carpenter and Demiralp's assertion that the response of the funds rate to supply shocks provides "strong evidence of a liquidity effect at the daily frequency." First, consistent with Figure 8, reserve supply shocks account for very little of the daily variability of the funds rate from the target. Indeed, if $v_{t}$ is omitted from the equation, $\bar{R}^{2}$ declines by less than 0.01 of a percentage point. Second, and most important, while the estimates suggest that large shocks to reserves are associated with changes in the equilibrium funds rate, such estimates provide no evidence for the more interesting and policy-relevant question of whether the Fed brings about permanent changes in the funds rate through open market operations. Indeed, the estimates suggest that it is unlikely that the Fed does this. There were only 554 days in the entire sample of 3,176 daily observations when the Desk deviated from its operating procedure by $\$ 2.0$ billion or more. Moreover, the estimates suggest that the largest deviation $(-\$ 9.19$ billion) would have generated about a 42-basispoint rise in the funds rate. Hence, these estimates suggest that it would take a series of relatively large open market operations in one direction to bring about the kind of changes in the equilibrium funds rate that the Fed is often credited with engineering. As I have already noted, there is no evidence that the Desk engaged in such open market operations upon changing the funds rate target.

\section{The Liquidity Effect and the Federal Funds Market}

As a general rule, the larger a single market participant's activities are in the market, the larger should be the effect of such activities on equilibrium price. Indeed, the hypothesis of atomistic market participants is a cornerstone of the com- 


\section{Figure 9}

\section{Thirty-Day Moving Average of Federal Funds Trading Volume}

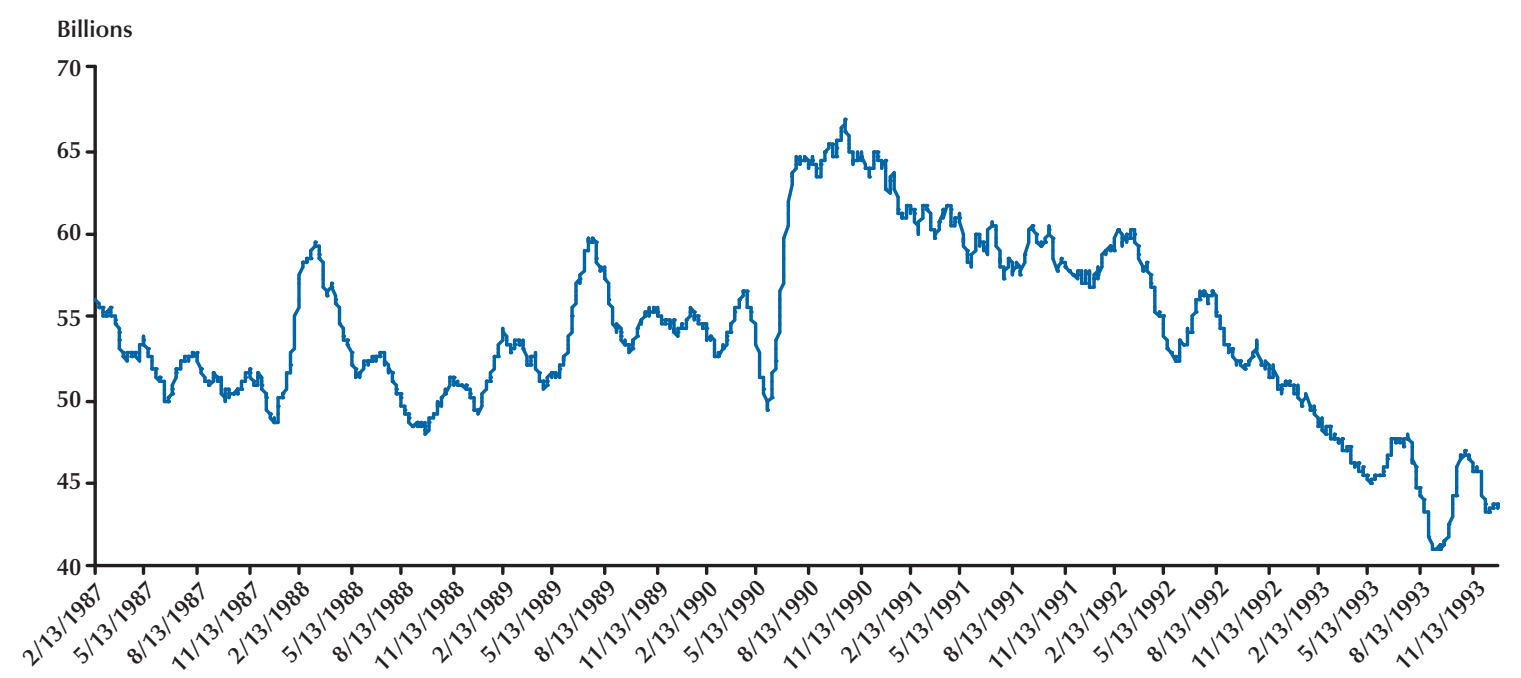

NOTE: Data are plotted on the last day of the moving average.

petitive market model. As a general rule, one would expect the Fed's ability to influence the federal funds rate to be positively related to the relative importance of its activities in the federal funds market—-the more liquidity the Fed provides to the market, the larger should be its ability to affect the equilibrium federal funds rate. Hence, some additional evidence on the potential for a liquidity effect can be obtained by investigating the relative importance of open market operations in the federal funds market.

Despite the importance of the federal funds rate in the conduct of monetary policy, surprisingly little is known about it. Federal funds transactions involve the purchase or sale of deposit balances at the Fed. Hence, direct market participation is limited to entities that hold deposits at the Fed. For the federal funds market, this means banks, Fannie Mae, Freddie Mac, and Federal Home Loan Banks. ${ }^{21}$ There are both brokered and non-brokered transactions in the market. ${ }^{22}$ Until recently, relatively little was known about

${ }^{21}$ Fannie Mae, Freddie Mac, and Federal Home Loan Banks are major players in the federal funds market and often have had zero or near zero balances with the Fed at the end of the day. the overall size of the market. Using estimated data from Fedwire funds transfers during the first quarter of 1998, Furfine (1999) estimates the average daily volume of federal funds transactions to be $\$ 144$ billion. Recently, Demiralp, Preslopsky, and Whitesell (2006) have used a modification of Furfine's methodology to estimate the size of the funds market over the period 1998-2003.

They find that the average daily volume of transactions in the funds market in the first quarter of 1998 was $\$ 145$ billion and that the daily volume of federal funds transactions increased until 2001 and then declined slightly.

Knowledge of the division of the market between brokered and non-brokered trading is less well known. Stigum (1990) suggested that the brokered funds market was about $\$ 70$ billion per day in the late 1980s; however, Furfine (1999) found that about 83 percent of the identified federal funds transactions were brokered.

The published federal funds rate is a quantityweighted average of transactions of a group of

\footnotetext{
22 See Stigum (1990), Furfine (1999), and Demiralp, Preslopsky, and Whitesell (2006) for discussions of various aspects of the federal funds market.
} 
brokers that report their transactions daily to the Federal Reserve Bank of New York. The 30-day moving average of the total volume of federal funds transactions reported by these brokers for the period January 1, 1987, through December 31, 1993, is presented in Figure 9. The trading volume hovered around $\$ 53$ billion from the beginning of 1987 to mid-1990 and then increased dramatically by about $\$ 10$ billion. Trading volume peaked in October 1990 and then began to decline. The initial decline in trading volume coincides with the elimination of reserve requirements on nonpersonal time and savings deposits, which reduced reserve demand by about $\$ 13.5$ billion. The sharp decline in 1992 also coincides reasonably well with the reduction in percentage reserve requirements from 12 to 10 percent. ${ }^{23}$ Why trading volume trends down beginning in 1991 is unclear, however.

In any event, these volume figures suggest that the brokers who report daily to the Federal Reserve Bank of New York account for a relatively small share of the brokered market—and an even smaller share of the total market. Indeed, based on Furfine's and Demiralp, Preslopsky, and Whitesell's estimates, the brokers that report daily to the Fed account for roughly about a third of the federal funds market.

Despite the possibility that the brokered transactions appear to represent a relatively small share of the federal funds market, these are the correct data for analyzing the relative importance of open market operations because these data are used to calculate the effective federal funds ratethe rate used in virtually all analyses of monetary policy.

The day-to-day variation in the volume of trading among these brokers is relatively large. There are only four days in this sample when the daily change in the trading volume is $\$ 5$ billion or less. In contrast, there were only 267 days (of the 3,176 days) where the absolute value of $O M O D$ was larger than $\$ 5.0$ billion. It is hardly surprising, therefore, that $O M O D$ accounts for almost none

\footnotetext{
${ }^{23}$ It is also the case that the number of brokers has changed over time. Unfortunately, there is no precise dating of changes in the number of participating brokers.
}

of the daily variation in the volume of federal funds transactions.

The relatively small size of open market operations alone may account for the results presented above. But there are other reasons for suspecting that the impact of open market operations on the funds rate is small. While seldom discussed in analyses of open market operations and the federal funds rate, in reality the link between open market operations and the funds rate is secondorder. Open market operations do not directly affect the supply of federal funds. Rather, they directly affect the supply of reserves available to banks. Banks need not automatically increase or decrease federal funds trading when open market operations alter the availability of reserves. Nevertheless, because the initial effect of open market operations is on the reserves of large banks, some of whom may act as brokers in the federal funds market, simultaneously buying and selling funds (e.g., Furfine, 1999), it is reasonable to assume that open market operations will likely affect the availability of funds in the market.

Nevertheless, it is important to remember that the volume of federal funds trading is determined by a variety of factors that are independent of daily open market operations. For example, Meulendyke (1998) notes that beginning in the 1960s, when short-term rates rose above Regulation Q interest rate ceilings, large banks began financing their longer-term lending in the overnight market. It is now recognized that many banks finance a significant part of their loan portfolio in the overnight markets. It is also well known that large banks tend to be net demanders of funds, while small banks tend to be net suppliers. Hence, daily changes in the volume of federal funds transactions are likely to be affected by changes in the distribution of deposit and reserve flows unrelated to daily open market operations.

Not only is the daily volume of federal funds transactions large relative to daily open market operations, it is many times larger than the overnight reserve balance at the Fed-the commodity being traded (e.g., Taylor, 2001). Although the exact source of the disparity between the flow of federal funds transactions and the stock of the 


\section{Table 5}

The Daily Change in Total Reserves: January 2, 1986-December 31, 1996

\begin{tabular}{|c|c|c|}
\hline Variable & Coefficient & Significance level \\
\hline Constant & -0.461 & 0.000 \\
\hline$\Delta E_{t-1} f\left(f f_{t}^{*}, x_{t}\right)$ & 0.688 & 0.000 \\
\hline$\Delta E_{t-1} N B R_{t}$ & 0.558 & 0.000 \\
\hline$v_{t}$ & 0.672 & 0.000 \\
\hline$\Delta B R_{t}$ & 0.846 & 0.000 \\
\hline$O M O D_{t}$ & 0.373 & 0.000 \\
\hline No. of observations & 2,677 & - \\
\hline Standard error & 2.7542 & - \\
\hline $\bar{R}^{2}$ & 0.2602 & - \\
\hline
\end{tabular}

commodity being traded is unclear, there can be little doubt that the flow of federal funds transactions is only weakly linked to the stock of the commodity being traded. ${ }^{24}$

Finally, since the early 1980s the Desk has followed the practice of entering the market once per day-before January 1987 this occurred at about 11:30 EST. Federal funds transactions occur continuously throughout the day. Indeed, spikes in the funds rate that are often associated with settlement Wednesdays are thought to be due to trading that occurs later in the day. In any event, if open market operations were to have a significant effect on the funds rate, one might expect the effect to occur around the time that the Desk is in the market. Hence, the extent to which these activities would affect the transactions-weightedaverage of transactions rates over the day is difficult to say.

Although the effect of open market operations on the funds market (and, consequently, the funds rate) is indirect and uncertain, their effect on total reserves is not. Moreover, conceptually, open

\footnotetext{
${ }^{24}$ The large flow of federal funds relative to the daily volume of balances at the Federal Reserve would appear to be inconsistent with Demiralp and Farley's (2005, p. 1132) characterization of open market operations and the equilibrium federal funds rate. They suggest that open market operations "are used to bring the supply of balances at the Federal Reserve in line with the demand for them at an interest rate (the federal funds rate) near the level specified by the Federal Open Market Committee (FOMC)."
}

market operations affect the funds rate by causing banks to buy or sell funds when the supply of reserves is decreased or increased, respectively, through open market operations. Hence, the relative importance of open market operations can be gauged by seeing how much of the variation in daily changes in total reserves they account for. To this end, changes in total reserves are regressed on changes in the Desk's estimate of reserve demand and reserve supply, changes in borrowing, errors in forecasting autonomous factors that affect reserves, and daily open market operations. The results, reported in Table 5, show that changes in total reserves are positively and significantly related to daily open market operations. Indeed, when $O M O D_{t}$ is deleted from the equation, $\bar{R}^{2}$ decreases from 0.2602 to 0.1736 , suggesting that $O M O D_{t}$ accounts for nearly 10 percent of the daily changes in total reserves. This simple analysis suggests that, while important, $O M O D_{t}$ 's contribution to changes in total reserves is quantitatively small. Given their relatively small effect on total reserves, it is not surprising that open market operations have an even smaller effect on federal funds.

\section{ANALYSIS AND CONCLUSIONS}

My analysis of the Desk's use of its operating procedure over the period March 1, 1984, through December 31, 1996, indicates that the Desk relied on the operating procedure in conducting daily open market operations. Indeed, the operating procedure alone accounts for nearly 40 percent of open market operations conducted during this period. The operating procedure and other factors-such as day-of-the-maintenance-period and day-of-the-year effects, differences between the funds rate and the funds rate target just prior to open market operations, and changes in the funds rate target-account for more than 50 percent of the variation in daily open market operations. Although large, these estimates indicate that there are other important factors that cause the Desk to deviate from its operating procedure.

Contrary to conventional wisdom-that the Fed controls the federal funds rate through open 
market operations-I find little support of an important liquidity effect at the daily frequency. While there is some evidence of a statistically significant negative relationship between reserve supply shocks and the funds rate, the relationship is weak. Consequently, to move the funds rate by 25 basis points or more, it appears that the Desk would have to conduct considerably larger open market operations than it has, in fact, conducted.

One possible reason for this finding is that changes in the funds rate target were anticipated. However, after conducting an extensive analysis of press reports, Poole, Rasche, and Thornton (2002, p. 73) found "little indication that the market was aware that the Fed was setting an explicit objective for the federal funds rate before 1989." This is not surprising in that Thornton (2006) shows that the FOMC was reluctant to acknowledge that it was targeting the funds rate. Moreover, Poole, Rasche, and Thornton (2002) show that the market frequently did not know that policy had changed when the Fed changed the target during 1989 and 1990 and that the target changes prior to 1994 were generally not predicted. Furthermore, prior to 1994, most funds rate target changes occurred during the intermeeting period (the period between consecutive FOMC meetings) and, hence, would have been difficult to predict exactly even if the market knew the Fed was targeting the funds rate and was expecting a target change. Consequently, it is extremely unlikely that rational expectations accounts for the lack of evidence of a liquidity effect.

Another possible explanation for the lack of evidence of a liquidity effect is that target changes are implemented over a period of several days, not immediately (e.g., Taylor, 2001). The analysis presented here finds no support for this explanation, however.

Yet another explanation for this finding is that open market operations account for a very small proportion of the variation in the equilibrium quantities in the reserves and federal funds markets. This explanation is supported by the fact that open market operations explain relatively little of the maintenance-period variation in total reserves and an extremely small amount of the daily variation in daily volume of federal funds transactions.

One explanation not investigated here is that some, and perhaps many, changes in the funds rate target are endogenous. Economic theory suggests that the Fed cannot control the natural rate of interest. Hence, when market forces bring about changes in inflation expectations or the real rate, the Fed can either change its target or permit policy to become inadvertently tighter or easier, depending on whether market forces are driving interest rates down or up. In any event, if target changes represent a response of the Fed to changing conditions that affect nominal interest rates rather than an exogenous change engineered to achieve some policy objective, the Desk would not necessarily have an incentive to add or drain reserves aggressively when the target is changed. Elsewhere (Thornton, 2004), I have presented evidence that many of the target changes identified in an influential paper by Cook and Hahn (1989) were endogenous. A proper investigation of this possibility during this period is left for future research.

Finally, I would note that evidence that the liquidity effect is small and statistically unimportant does not mean that the Fed could not move interest rates if it desired. It merely suggests that the Fed has not done so. Given their direct effect on reserves and the corresponding effect of changes in reserves on banks, one can understand why the Fed might be reluctant to engage in large open market operations. This reluctance would be particularly strong if the Fed is a small enough player in the credit market that it would take very large open market operations to generate significant changes in the equilibrium short-term rates.

\section{REFERENCES}

Carpenter, Seth and Demiralp, Selva. "The Liquidity Effect in the Federal Funds Market: Evidence from Daily Open Market Operations.” Journal of Money, Credit, and Banking, June 2006, 38(4), pp. 901-20.

Cook, Timothy and Hahn, Thomas. "The Effect of Changes in the Federal Funds Rate Target on Market 


\section{Thornton}

Interest Rates in the 1970s." Journal of Monetary Economics, November 1989, 24(3), pp. 331-51.

de Jong, Robert and Herrera, Ana Maria. "Dynamic Censored Regression and the Open Market Desk Reaction Function.” Unpublished manuscript, 2004.

Demiralp, Selva and Farley, Dennis. "Declining Required Reserves, Funds Rate Volatility, and Open Market Operations." Journal of Banking and Finance, May 2005, 29(5), pp. 1131-52.

Demiralp, Selva and Jorda, Oscar. "The Announcement Effect: Evidence from Open Market Desk Data.” Economic Policy Review, May 2002, 8(1), pp. 29-48.

Demiralp, Selva; Preslopsky, Brian and Whitesell, William. "Overnight Interbank Loan Markets." Journal of Economics and Business, January/ February 2006, 58(1), pp. 67-83.

Friedman, Benjamin M. "The Future of Monetary Policy: The Central Bank as an Army with Only a Signal Corps?" International Finance, November 1999, 2(3), pp. 321-38.

Furfine, Craig H. "The Microstructure of the Federal Funds Market." Financial Markets, Institutions $\mathcal{E}$ Instruments, December 1999, 8(5), pp. 24-44.

Hamilton, James D. "Measuring the Liquidity Effect." American Economic Review, March 1997, 87(1), pp. 80-97.

Meulendyke, Ann-Marie. U.S. Monetary Policy \& Financial Markets. Federal Reserve Bank of New York, 1998.

Pagan, Adrian R. and Robertson, John C. "Resolving the Liquidity Effect.” Federal Reserve Bank of St. Louis Review, May/June 1995, 77(3), pp. 33-54.

Poole, William; Rasche, Robert H. and Thornton, Daniel L. "Market Anticipations of Monetary Policy Actions.” Federal Reserve Bank of St. Louis Review, July/August 2002, 84(4), pp. 65-93.

Sternlight, Peter D. "Monetary Policy and Open Market Operations during 1990.” Federal Reserve
Bank of New York Quarterly Review, Spring 1991, 16(1), pp. 52-78.

Sternlight, Peter D. "Monetary Policy and Open Market Operations during 1991.” Federal Reserve Bank of New York Quarterly Review, Spring 1992, 17(1), pp. 72-95.

Stigum, Marcia. The Money Market. Third Edition. New York: McGraw-Hill, 1990.

Taylor, John B. "Expectations, Open Market Operations, and Changes in the Federal Funds Rate.” Federal Reserve Bank of St. Louis Review, July/August 2001, 83(4), pp. 33-47.

Thornton, Daniel L. "The Effect of Monetary Policy on Short-Term Interest Rates.” Federal Reserve Bank of St. Louis Review, May/June 1988, 70(3), pp. 53-72.

Thornton, Daniel L. "Identifying the Liquidity Effect at the Daily Frequency." Federal Reserve Bank of St. Louis Review, July/August 2001a, 83(4), pp. 59-78.

Thornton, Daniel L. “The Federal Reserve’s Operating Procedure, Nonborrowed Reserves, Borrowed Reserves and the Liquidity Effect." Journal of Banking and Finance, September 2001b, 25(9), pp. 1717-39.

Thornton, Daniel L. "The Fed and Short-Term Rates: Is It Open Market Operations, Open Mouth Operations or Interest Rate Smoothing?" Journal of Banking and Finance, March 2004, 28(3), pp. 475-98.

Thornton, Daniel L. “A New Federal Funds Rate Target Series: September 27, 1982-December 31, 1993.” Working Paper 2005-032A, Federal Reserve Bank of St. Louis, 2005.

Thornton, Daniel L. "When Did the FOMC Begin Targeting the Federal Funds Rate? What the Verbatim Transcripts Tell Us." Journal of Money, Credit, and Banking, December 2006, 38(8), pp. 2039-71. 